\title{
CHARACTER GROWTH MINDSET ENHANCEMENT IN EXTRACURRICULAR ACTIVITIES: AN INTERNATIONAL STUDY
}

\author{
Manuel Joaquín Fernández González \\ University of Latvia, Latvia
}

\begin{abstract}
This paper is based on a virtue education intervention implemented by faith-based NGOs from Latvia, Estonia, Finland and Sweden in July 2018, which focused on participants' $(N=43)$ character growth mindset, i.e., the believe that everyone, including oneself, can become a better person. The research question was: What impact does participation in a oneweek after school summer camp have on the development of 10-15-year-old participants' character growth mindset? The research adopted quasi-experimental approach using pre-test and post-test questionnaires and interviews. The intervention was found to have a positive impact on participants' character growth mindset, in particular regarding their perceived knowledge about how to become better persons and their belief that everybody can become a better person. Such extracurricular programs have the potential of enhancing children's disposition and 'know-how' to grow in virtue.
\end{abstract}

Keywords: Character growth mindset; Extracurricular activities; Moral education; Relational-selfof-virtue; Virtue growth.

\section{Introduction}

Pre-adolescence is a key period in moral identity development (Hart, \& Fegley, 1995), because "early experiences seem to play a pivotal role in the formation of an ideological framework that encompasses issues of morality, which are closely affiliated to the self" (Matsuba, \& Walker, 2005, 294). Interventions in extra-curricular activities (Birdwell, \& Wybron, 2014; Scott, Reynolds, \& Cadywould, 2016), also called "co-curricular" (Arthur, Kristjánsson, Harrison, Sanderse, \& Wright, 2017, 96), are closely linked to children's character building (Harrison, Morris, \& Ryan, 2016, 133-134). Many parents seek to develop children talents and personality during afterschool activities, adopting the so called "concerted cultivation" parenting style (Lareau, 2003; Vincent, \& Maxwell, 2016).

Several NGOs based on Christian values, which collaborate with parents in children education by organizing educational activities, are 
willing to professionalize their voluntary work (Baumgart-Ochse, \& Wolf, 2018; Boan, Aten, Greener, \& Gailey, 2016). The idea of this project was to collaborate with an international network of faith-based NGOs during a summer camp which provided participants leisure activities and Christian values education. The aim of the collaboration was twofold: enhancing NGO professionalization, and piloting and testing the impact of an original intervention in the field of virtue education.

Constructive alignment theory (Biggs, 2011) was used for creating the collaboration program, because its adaptability to short interventions like this one, contrarily to other existing models (e.g., Brunner's spiral curriculum approach: see Wright, Morris, \& Bawden, n.d., 7). Therefore, the intervention design was aligned with the definition of the educational goals and the choice of evaluation methods. The challenge was to define such a goal that would contribute to children's virtue development, and that could simultaneously be realistically addressed during an intervention whose results could be reached and measured in a short time (the length of a summer camp). After joint discussion, considering that "ultimately, the goal of character education, and all comprehensive and enlightened education, is for students to become better people" (Berkowitz, \& Bustamante, 2013, 12), it was decided to focus on children's understanding of the possibility of "becoming better persons".

\section{Theoretical background}

Recently, the project "Character in Transition" showed that 10-12 yearsold viewed the development of character and values as important to them (Arthur, Davison, See, \& Knowles, 2009). The theoretical background of the intervention was the concept of relational-self-of-virtue (Fernández González, 2019): the personal deep disposition to virtue growth in communities of virtue. Four components interact in the formation of a relational-self-of-virtue: the cognitive and emotional shaping of an ideal relational-self-of-virtue (including beliefs about character growth), the commitment to relational virtue growth (conational component), involvement in virtue growth in communities of virtue (phronesisguided behavioural component), and a socially situated virtue identity (emotional-evaluative component). Due to time constraints, the focus of the intervention/evaluation was on the cognitive-emotional component, concretely on: 1) character growth mindset (believing on the possibility of improving character, for oneself and for others); and 2) character growth practical knowledge (knowing what to improve and how to do it). It should be noted that this kind of practical knowledge differs from the virtue of phronesis, which, according to Aristotle, is a judgement of 
the practical reason about what to do here and now. The cognitive aspects are particularly relevant in early moral development stages: "What is of greater importance is that children learn about the process of acquiring and developing virtue" (Harrison., Morris, \& Ryan, 2016, 71).

The research question guiding the inquiry and the design of the intervention was: What impact does participation in a one-week after school summer camp have on the development of 10-15-year-old participants' character growth 'mindset' and character growth 'practical knowledge' (know-how)?

\section{Description and implementation of the intervention}

The cognitive content of the intervention drew from the concept of "the drive to aspire" (Annas, 2011), including a Christian perspective: God's help for developing virtue (Council, 1994, No. 2013). Considering that "to grow in understanding of how to act well" is also part of the "virtue practice" area (Jubilee Centre, n.d., 6), during the intervention, a "daily topic" was decided in order to help children to focus on developing it during the day. The formulation of the daily topic was based on interpersonal competence (Park, Tsukayama, Goodwin, Patrick, \& Duckworth, 2017) and on civic virtues (Jubilee Centre, 2017) (e.g., interpersonal self-control, cheerfulness, service, gratefulness).

The intervention plan (including the definition of its goal and contents) was designed jointly by the researcher and the NGO staff before the summer camp, resulting in a combination of "researcher-derived" and "practitioner-derived" program (Urban, Hargraves, \& Trochim, 2014). It combined "taught" and "caught" elements. The "taught" elements included learning activities aligned with the educational goal and the evaluation methods (Biggs, 2011): a lecture about the daily topic (15 minutes per day, by country groups); individual "character growth coaching" (5-7 minutes, at the beginning and the end of the camp); and a daily guided reflection time (5 minutes, by country groups), in which 3 questions regarding the daily topic were read aloud with silent intervals; a "Character Growth Card" for personal use, (adapted from Duckworth, Tsukayama, \& Patrick, 2014) ${ }^{1}$ containing 3-4 growth indicators for each daily topic; and the initial questionnaire, which familiarized children with the intervention topics. The "caught" elements were: leaders' and volunteers' modelling; posters illustrating the daily topic (renewed every morning); background

\footnotetext{
${ }^{1}$ https://www.greatschoolspartnership.org/wp-content/uploads/2016/11/ January2014CharacterGrowthCard.pdf
} 
songs with related content during sports and games; and staff T-shirts with the camp slogan ("Dare, Change, Grow!"). As an example, on day 3 the topic was 'Joy and good atmosphere', the slogan: 'Good friends are happy friends!', the songs of the day were "Easy Love" (Sigala), "Waving flag" (WordCup-2018) and "Euro 2016"; and on day 4 the topic was 'spirit of service', the slogan was 'Helping others is growing twice!', and the songs of the day were "I'm here for you" (Kygo) and "Lay all on me" (The Rudimental).

The intervention plan was informed by evidence drawn from different scientific sources. The centrality of modelling in character education is widely accepted (e.g., Arthur et al., 2017, 102-104; Berkowitz, \& Bustamante, 2013, 13-14). The choice of short lectures and personal coaching was based on good results obtained in previous years and in recent research (Jubilee Centre, n.d., 10-11). "Time for personal reflection" (Arthur, \& Harrison, 2014, 35) was included because "self-examination makes up an important component of "virtue practice"" (Wright, Morris, \& Bawden, n.d., 10). Using posters is a widely used technique to "make character education visible" (Arthur, \& Harrison, 2014, 34), and background music addressed the emotional component of the intervention. The draft of the intervention plan was discussed with the organizers for "viable validity" (Chen, 2010), a bottom-up approach to validity considering "practitioners' views and experience regarding whether an intervention program is practical, affordable, suitable, evaluable, and helpful in the real-world" (p. 207).

Regarding the implementation of the intervention, it took place during the last week of July 2018 within a summer camp with 45 boys (10 to 15 y/o) from 4 countries (Latvia, Estonia, Finland and Sweden) at Malminharju (Heinola, Finland). The staff included 7 volunteers and 7 leaders from those countries. Leisure activities included sports, games, swimming and free time. The good weather helped to have a nice atmosphere. The material aspects were well managed, as it was the $5^{\text {th }}$ edition of the camp.

Intervention materials (growth cards, posters, outlines of lectures, daily reflection questions and questionnaires) were prepared beforehand for sparing time during the camp. Great importance was given to the involvement of the staff, to reinforce their 'buy-in' into the project: before the camp, the staff translated intervention materials in their national language, developed the lecture outlines, chose the daily songs, and introduced changes in the schedule proposal. On the day of arrival, the researcher explained the staff again the intervention goals and means and provided support materials (explanation of "character growth mindset" concept and a list of "beliefs of growth mindset facilitator"). During the camp, leaders leaded the lectures, coaching, and reflection times, and volunteers took care of posters, music, and leisure activities climate. 


\section{Methodology}

Research methods. A survey research design (Robson \& McCartan, 2016, 243) was chosen for impact evaluation. Using mixed methods seemed the best way to answer the research question (Denscombe, 2014). The voices of children and volunteers, and the professional judgement of leaders were triangulated (Harrison, Arthur, \& Burn., n.d., 17-18). Two different questionnaires for participants and leaders, and semi-structured interviews with volunteers were used. The research instruments were designed in alignment with the intervention activities and the educational goals (Biggs, 2011).

The research adopted a quasi-experimental approach without control group (Cohen, Manion, \& Morrison, 2011), using pre-test for baseline identification and post-test for measuring the differences at the end line. The hypothesis was that the intervention will make a difference in children's character growth mindset and character growth practical knowledge.

Research instruments. The pre-test questionnaire had 24 items addressing children's mindset and practical knowledge about character growth. The questionnaire had two sections: 9 "belief questions" (in a 5-point scale), and 15 "positioning statements" (in a 7-point scale). The questions addressing children growth mindset were adapted from the "Character Growth Mindset Scale" (Dweck, 2000). The questions addressing their "know-what" and "know-how" were based on the interpersonal section of the standardized "Character Growth Card" (Duckworth, Tsukayama, \& Patrick, 2014) and were related to the "daily topics" that were decided for each day. On the $3^{\text {rd }}$ day, the researcher shared with each country leader the pre-test findings for his country, and they discussed concrete "actions on the findings" (Harrison, Arthur, \& Burn, n.d., 67). Even if the "feedback loop" (p. 17) was very short (there were only 4 days left till the end of the camp), it helped to adapt the contents of the remaining coaching sessions and daily lectures.

The post-test was identical to the pre-test, with some exceptions: an ambiguous question was slightly reformulated (item A6); a final section asking participants to rate in a 7-point scale the appropriateness of intervention activities was added; and 6 items whose pre-test average level was very high were removed (so, only 18 items were compared).

The questionnaire for leaders included questions about the impact of the intervention on children's beliefs (7 items in 5-point scale, parallel to the first section of the post-test) and about the perceived effectiveness of intervention activities (7 items, 7-point scale, parallel to the final section of post-test). The interview schedule addressed volunteers' motivations, preparation, understanding of the central idea of the camp, received 
support, perceived personal improvement and respondents' suggestions for the future.

Data collection and analysis. The researcher leaded the pre-test in the bus of the camp during the last part of the trip (Helsinki - Maminharju), and the post-test in the participants' lodgement right at the end of the camp, for avoiding external contamination of results. The average time for completing each questionnaire was 12-15 minutes. Leaders' questionnaires were collected 2 to 5 days after the camp by email. The data were analysed using SPSS 21. The data set reliability was high (Cronbach's Alpha $=$.939). The Shapiro-Wilk test of normality, appropriate for small sample size $(n<50)$, showed that data were non-normally distributed, so non-parametric tests were used in the analysis. Interviews with volunteers lasted 8-10 minutes each, and they were done the last day of the camp. They were audio-taped, transcriber and analysed using MS Word software.

\section{Research limitations and ethical considerations}

Limitations of the research. Reliance on participants self-report is a major limitation of the study (Duckworth, \& Yeager, 2015). Triangulation of children's, volunteers' and leaders' voices, which intended enhance reliability, was still based on their subjective views. However, "given the nature of 'virtue', there is really only one person who can say with any confidence whether they feel they are growing as a person...- and that is the student alone" (Wright, Morris, \& Bawden, n.d., 18). During interviews and in open questions, staff mentioned randomly observed children behaviours supporting their views, but these were not structured and reliable observations.

The reliability of impact evaluation based in pre-post-test is limited because both questionnaires were not exactly identical. Moreover, "the correlation may be spuriously affected by the candidate's memory of having taken the same test a short time ago" (Arthur, Waring, Coe, \& Hedges, 2012, 50; Duckworth, \& Yeager, 2015). However, after a week full of different activities, probably children did not remember exactly how they rated the questions initially.

Other limits were the absence of a control group, the lack of time perspective to know how persistent the acquired knowledge will be, and social desirability bias, particularly strong at those ages. Collecting pretest data at the end of the trip was convenient, but children who travelled longer were probably tired. In addition, the proximity of the end may have affected children concentration during the post-test. The "purity of the intervention" (Duckworth, \& Yeager, 2015) was quite high, because of the absence of external social interaction, excepting participants' phone call to their parents. However, conversations among children and other 
possible internal factors might have had an influence on children answers. In reasons of these limits, and of the reduced sample, the research findings are not generalizable.

Ethical considerations. Country leaders sent parents/guardians the research summary, requesting their consent for children participation. Children informed consent was also requested, and only those who wanted freely participated. Two children decided not to participate. For confidentiality reasons, analysis was done at group level, not individual level. For matching pre-test and post-test, each questionnaire had a confidential participant code known only by the researcher. Interview transcripts contained participants' pseudonyms. A summary of the findings was sent to the leaders for further action improving the next editions of the camp and for enhancing staff's professional development (Harrison, Arthur, \& Burn., n.d., 18).

\section{Findings}

43 children participated in the research. Half of them were from Estonia ( $N=23,53.5 \%$ ), and the rest were quite equally distributed between Latvia, Finland and Sweden. Children were between 10 and $15.5 \mathrm{y} / \mathrm{o}$ (Mean = 12,8). We present below the results for the sections "belief questions" and "positioning statements" of children questionnaires, commenting the findings on the light of the leaders' and volunteers' views. Regarding changes in children's beliefs in the section "questions", see in Figure 1 the pre- and post-test results (in a 5-point scale).

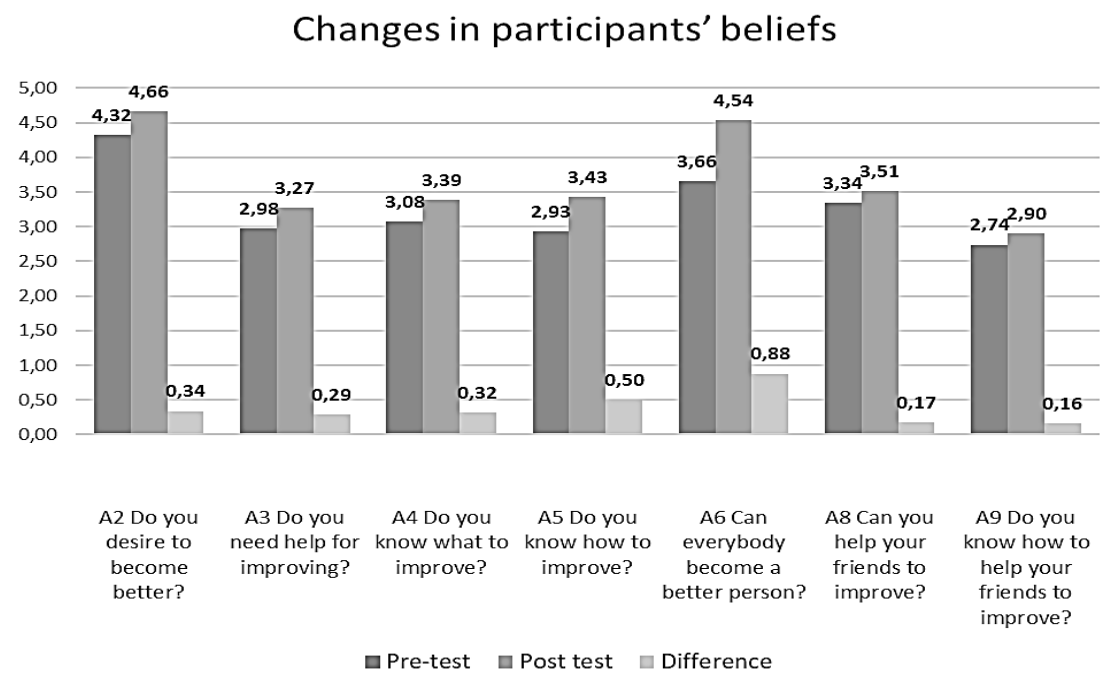

Figure 1. Character growth mindset "beliefs": Pre-test, post-test, Mean differences 
In both the pre-test and post-test, the questions A2 ("Do you think that you have the desire of becoming a better person?") and A6 ("Do you think that everybody can become a better person?") were rated the highest, but the lowest rated was A9 ("Do you know how to help your friends to become better persons?"). Comparing pre-test and post-test, the mean for each question was slightly higher after intervention. The lowest increment was in questions A9 (Mean increase: + 0.16 in 5-point scale) and A8 ("Do you think that you can help your friends to improve as persons?": $+0,17$ ), both related to helping others. The biggest increment was in questions A6 ( +0.88 , maybe due to its reformulation in the post-test) and A5 ("Do you know how to improve your personality?": +0.50). The relatively low increments observed in all criteria could be due to chance. For testing their statistical significance, the nonparametric Wilcoxon (paired) signedrank test was the most appropriate (Cohen, Manion, \& Morrison, 2011), because it was possible to match each student's pre-test and post-test scores. Statistically significant differences were found only in criteria A5 $(p=.008)$ and A6 ( $\mathrm{p}=.002)$.

Triangulating the changes found on children's beliefs (see Figure 1, column "Difference") with leaders' opinions about the impact of the intervention on children beliefs (see Table 1), it was found that, for both of them, the highest impact (change) was on criterium A6, and the lowest one - on criteria A8 and A9. There was no coincidence of data about criteria A5 (for children it was the $2^{\text {nd }}$ biggest change, but for leaders it came in $4^{\text {th }}-5^{\text {th }}$ place).

Table 1. Intervention impact on participants' growth mindset change: Leaders' opinions

\begin{tabular}{|l|c|c|}
\hline ¿Do you think that the intervention helped the children... & $\begin{array}{c}\text { Mean } \\
\text { (5-point } \\
\text { scale) }\end{array}$ & S.D. \\
\hline A2 ...to increase their desire of becoming a better person? & 4.0 & .58 \\
\hline $\begin{array}{l}\text { A3 ...to understand better that they need help for improving them- } \\
\text { selves? }\end{array}$ & 3.9 & .69 \\
\hline $\begin{array}{l}\text { A4 ...to know better what they should improve to become a better } \\
\text { person? }\end{array}$ & 4.0 & .82 \\
\hline A5 ...to know more concretely how to improve their personality? & 3.9 & .69 \\
\hline $\begin{array}{l}\text { A6 ...to understand better that everybody can become a better } \\
\text { person? }\end{array}$ & 4.4 & .53 \\
\hline $\begin{array}{l}\text { A8 ...to understand better that they can help their friends to im- } \\
\text { prove as persons? }\end{array}$ & 3.4 & .79 \\
\hline $\begin{array}{l}\text { A9 ...to know more concretely how to help their friends to become } \\
\text { better persons? }\end{array}$ & 3.0 & .82 \\
\hline
\end{tabular}


Regarding changes in children (dis-)agreement with the given statements about how to become a better person, see in Figure 2 the comparison of pre-test and post-test results.

\section{Changes in participants' "Know how" (7-point scale)}

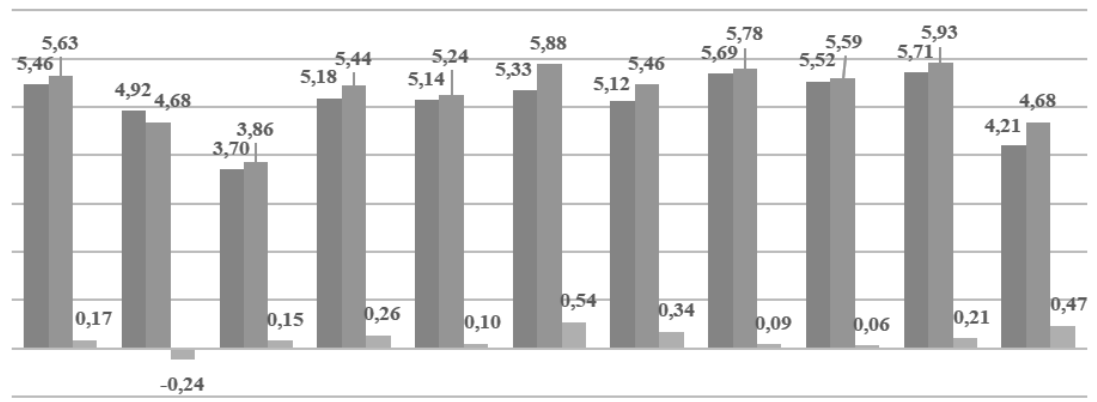

$$
\begin{aligned}
& \text { B1 I can B2 my B3 B4 trying B5 I have B6 Trying B7 being B8 for B12 when B13 when B14 } \\
& \text { become efforts and without not to good to show often growing I I forgive, I I serve praying } \\
& \text { better God's God I complain reasons to joy helps angry have to become with joy, I helps me } \\
& \text { having fun help are cannot helpsme grow me to means that think better become to grow } \\
& \text { necessary grow to grow grow Ineed to about better } \\
& \text { - Pre-test } \square \text { Post test Difference }
\end{aligned}
$$

Figure 2. Character growth "know-how": Pre-test, post-test, Mean differences

In both pre-test and post-test, children's highest agreement was with statement B13 ("When I help others and serve them with joy, I become a better person"), and the lowest - with B3 ("Without God's help I cannot improve myself at all"). Comparing pre-test and post-test, the mean for each statement was also slightly higher after intervention, except for the statement B2 ("For becoming a better person, I absolutely need to make efforts and to ask God for help"), in which the post-test was slightly lower (Mean decrease: -0.24 in a 7-point scale). The biggest increment was in statements B6 ("When I make efforts to smile and to be cheerful, I become a better person and I help others to become better persons": + 0.54) and B14 ("To pray helps me very much to become a better person": +0.47). These differences were not statistically significant (B6: $\mathrm{p}=.076 ; \mathrm{B} 14: \mathrm{p}=.160$ ).

Summarizing, it seems that children participating in the intervention had a (not statistically significant) tendency to demonstrate higher character growth mindset and practical knowledge in the post-test.

\section{Discussion}

The high impact of the intervention on participants' conviction that making efforts to be cheerful helps them and their friends to become 
better persons (item B6) has a particular resonance with the theory of the relational-self-of-virtue (Fernández González, 2019). Cultivating a relational-self-of-virtue implies a particular kind of motivation, i.e., growing in virtue for the sake of others, in order to help them better to grow in virtue and to establish more caring relations with them. In addition, according to this theory, caring for others' growth in virtue is a privileged way of developing one's own full potential for virtue growth. On the other hand, the low impact observed in other relational criteria, such as knowing how to help others (A8 and A9), thinking about others (B8) and forgiving others (B12), indicates that children need guidance to develop this aspect of the relational-self-of-virtue. This finding could indicate that caring for others is a characteristic feature of latter stages of moral development. This confirms the Aristotelian theory of the five stages of moral development as described by the Jubilee Centre (Jubilee Centre, n.d., 7-9): the feature "I can actively help to build up others in virtue" corresponds to the Stage 5 of moral development, whereas the intervention addressed rather a feature corresponding to the Stage 1, namely: "to rethink the strength of commitment to character growth".

Overall, the intervention had a positive impact on participants' character growth mindset, in particular regarding their perceived knowledge about how to become better persons (A5) and their conviction that everybody can become a better person (A6). In their interviews, the volunteers discussed some aspect that in their opinion enhanced the impact of the intervention. One of them was the centrality of the example of the staff and volunteers, and of young participants themselves. In an open question, a leader commented on the relevance of good example: "I think that youngest boys involve in becoming better persons when they are inspired by their own friends and by youngsters who are just a bit older than them" (a leader). This confirms that "we develop virtues almost by accident... through observing how others live and emulating or rejecting how they go about life." (Jubilee Centre, n.d., 3). Young volunteers' modelling was particularly effective, because they were "near peers" to the children (Harrison, Morris, \& Ryan 2016, 147). Their work corresponded to the highest level ('enhancing') indicators of the 'School Ethos Self-Evaluation Framework' (see section "Whole School Community" in Harrison, Arthur, \& Burn, n.d., 32 and 57): they all were aware of the focus of the intervention, integrate it into the context of activities, purposefully modelled the behaviours expected by the camp ethos, and actively acted as role models to the children, who accepted them as such.

However, for some volunteers it was hard to say if the intervention really helped the children: "I helped in specific situations, but I do not know if a specific situation really helps. I mean, you need to do things multiple 
times before you really improve" (a volunteer). Most of them believed they somehow helped the children to understand the main idea of the camp: "I think yes [it helped], because...they are still kids, and when they lose they get discouraged, complain, start bordering their colleagues... these are very good occasions to help them to think that they should be kind and help those who are not so skilled" (a volunteer). As one of the leaders summarized: "I do not think that the research itself... marked a difference. However, the good preparation of the contents of the intervention, and the good example they saw, has certainly helped children to grow, even if it is not quantifiable" (a leader). Finally, all leaders stressed that the intervention helped to professionalize their work, which was one of the goals of the collaboration: "definitively, it was a step forward... it was very good to have an integrated educational plan that embrace everything" (a leader), and "the parents perceived it in a very positive way" (a leader).

\section{Conclusion and recommendations}

Building on two emotional-cognitive aspects of relational-self-ofvirtue theory (character growth 'mindset' and character growth 'practical knowledge'), this intervention aimed at helping children to understand better that everyone can improve his/her character (including themselves), and to improve their practical knowledge about what to improve and how to do it. The intervention contained "taught" and "caught" elements, including group lectures and reflection time, individual coaching, an adapted "Character Growth Card", visual materials and, most important, the modelling of a team of 14 leaders and young volunteers highly identified with the formative goal of the intervention. The intervention impact was evaluated through the voices of children, volunteers and leaders, using triangulation of quantitative (questionnaires) and qualitative (interviews, open questions) methods. The intervention had a relative positive impact on children's character growth mindset and practical knowledge, in particular on their opinions about the possibility for everyone to become a better person.

This pilot intervention contributed to professionalize the NGOs work, and its implementation and assessment procedures could be used in future similar camps. Considering the limits of the study, some recommendations for next steps were put forward: This study relied mostly on participants' self-reports; therefore, for enhancing reliability, using observations and moral dilemmas could be advisable in the future. More separation between pre-test and post-test, for example during a semester, could provide stronger evidence about the impact of the intervention. Using a control group in a future research could be useful for enhancing reliability. A longitudinal 
study for controlling the persistence of the learned lessons over time (6 months or more) would be necessary.

It could be concluded that such a program, with the necessary improvements, might probably enhance children's sustainable understanding of the possibility of growing in virtue and how to do it, which could motivate them to develop further their own character, and to help their friends to do so.

\section{Acknowledgements}

Project financed by the European Regional Development Fund. Postdoctoral project number 1.1.1.2/VIAA/1/16/071.

\section{References}

Annas, J. (2011). Intelligent Virtue. Oxford: Oxford University Press.

Arthur, J., Davison, J., See, B. \& Knowles, C. (2009). Character in Transition - Consistency in Values: The Transition from Primary to Secondary School. Not Known. https://research. birmingham.ac.uk/portal/files/2920384/Character_in_transition_full_report_with_cover. pdf (05.06.2019).

Arthur, J., \& Harrison, T. (2014). Schools of Character. Birmingham: University of Birmingham, Jubilee Centre for Character and Virtues. https://www.jubileecentre. ac.uk/userfiles/jubileecentre/pdf/character-education/SchoolsOfCharacterPDF.pdf (05.06.2019).

Arthur, J., Kristjánsson, K., Harrison, T., Sanderse, W., \& Wright, D. (2017). Teaching Character and Virtue in Schools. London: Routledge.

Arthur, J., Waring, M., Coe, R., \& Hedges, L. (2012). Research Methods \& Methodologies in Education. London: Sage.

Baumgart-Ochse, C., \& Wolf, K. D. (2018). Conclusions: Religious NGOs: Mediators between Distinctiveness and Alignment. In: C. Baumgart-Ochse, \& D. Wolf (Eds.), Religious NGOs at the United Nations (pp. 198-208). London: Routledge.

Berkowitz, M. W., \& Bustamante, A. (2013). Using Research to Set Priorities for Character Education in Schools: A Global Perspective. KEDI Journal of Educational Policy, Special Issue, 7-20.

Biggs, J. B. (2011). Teaching for Quality Learning at University: What the Student Does. London: McGraw-Hill Education.

Birdwell, J., \& Wybron, I. (2014). Scouting for Skills. London: DEMOS. www.demos. co.uk/publications/scoutingforskills (05.06.2019).

Boan, D. M., Aten, J., Greener, S., \& Gailey, R. (2016). The Well-Prepared International Development Worker. Missiology, 44(4), 430-447.

Chen, H. (2010). The Bottom-Up Approach to Integrative Validity: A New Perspective for Program Evaluation. Evaluation and Program Planning, 33(3), 205-214.

Cohen, L., Manion, L., \& Morrison, K. (2011). Research Methods in Education. $7^{\text {th }}$ ed. London: Routledge. 
Council, S. V. E. (1994). Catechism of the Catholic Church. Vatican City: Libreria Editrice Vaticana. http://www.vatican.va/archive/eng0015/_index.htm (05.06.2019).

Denscombe, M. (2014). The Good Research Guide. $5^{\text {th }}$ ed. Berkshire: Open University Press.

Duckworth, A. L., \& Yeager, D. S. (2015). Measurement Matters: Assessing Personal Qualities other than Cognitive Ability for Educational Purposes. Educational Researcher, 44(4), 237-251.

Duckworth, A. L., Tsukayama, E., \& Patrick, S. D. (2014). A Tripartite Taxonomy of Character. In: Annual Meeting of the American Educational Research Association, April 3-7 2017, Philadelphia, PA. https://www.researchgate.net/profile/Angela_ Duckworth2/publication/280529814_A_tripartite_taxonomy_of_character/links/ 55b7905208aed621de046a66.pdf (05.06.2019).

Dweck, C. S. (2000). Self-Theories: Their Role in Motivation, Personality, and Development. Philadelphia, PA: Psychology Press.

Fernández González, M. J. (2019). At the Heart of Virtue Growth: 'Self-ofVirtue' and 'Virtue Identity'. Estudios sobre Educacion 36, 9-29. https://doi. org/10.15581/004.36.9-29.

Harrison, T., Arthur, J., \& Burn, E. (n.d.). Character Education: Evaluation Handbook for Schools. Birmingham: University of Birmingham, Jubilee Centre for Character and Virtues. https://www.jubileecentre.ac.uk/1721/character-education (05.06.2019).

Harrison, T., Morris, I., \& Ryan J. (2016). Teaching Character in the Primary Classroom. London: Sage.

Hart, D., \& Fegley, S. (1995). Prosocial Behavior and Caring in Adolescence: Relations to Self-Understanding and Social Judgment. Child Development, 66, 1346-1359.

Jubilee Centre for Character and Virtues. (2017) A Framework for Character Education in Schools. Birmingham: University of Birmingham, Jubilee Centre for Character and Virtues. http://jubileecentre.ac.uk/userfiles/jubileecentre/pdf/character-education/ Framework\%20for\%20Character\%20Education.pdf (05.06.2019).

Jubilee Centre for Character and Virtues. (n.d). Primary Programme of Study - Teachers' guide. Birmingham: University of Birmingham, Jubilee Centre for Character and Virtues. https://www.jubileecentre.ac.uk/userfiles/jubileecentre/pdf/Primary\%20 Programme\%20of\%20Study/Primary_Teacher's_Guide.pdf (05.06.2019).

Lareau, A. (2003). Unequal Childhoods. Berkley: University of California Press.

Matsuba, M. K., \& Walker, L. J. (2005). Young Adult Moral Exemplars: The Making of Self through Stories. Journal of Research on Adolescence, 15(3), 275-297.

Park, D., Tsukayama, E., Goodwin, G. P., Patrick, S., \& Duckworth, A. L. (2017). A Tripartite Taxonomy of Character: Evidence for Intrapersonal, Interpersonal, and Intellectual Competencies in Children. Contemporary Educational Psychology, 48, 16-27.

Robson, C., \& McCartan, K. (2016). Real World Research. Chichester: John Riley and Sons Ltd.

Scott, R., Reynolds, L., \& Cadywould, C. (2016). Character by Doing: Evaluation. London: Demos. 
Urban, J. B., Hargraves, M., \& Trochim, W. M. (2014). Evolutionary Evaluation: Implications for Evaluators, Researchers, Practitioners, Funders and the Evidence-Based Program Mandate. Evaluation and Program Planning, 45, 127-139.

Vincent, C., \& Maxwell, C. (2016). Parenting Priorities and Pressures: Furthering Understanding of 'Concerted Cultivation'. Discourse: Studies in the Cultural Politics of Education, 37(2), 269-281.

Wright, D., Morris, I., \& Bawden, M. (n.d.) Character Education: A Taught Course for 11 to 16 Year Olds - Teacher's Guide. Birmingham: University of Birmingham, Jubilee Centre for Character and Virtues. https://www.jubileecentre.ac.uk/userfiles/jubileecentre/pdf/ TaughtCourse/TC-teachers-guide.pdf (05.06.2019). 